JURNAL MANAJEMEN PENDIDIKAN

Volume 07 Nomor 01 Januari 2019

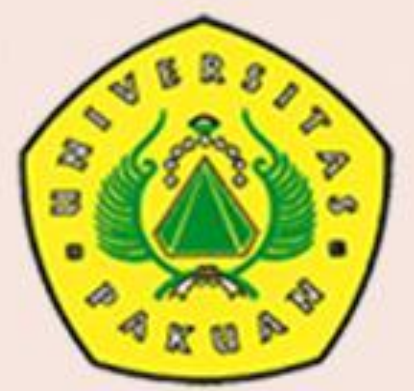




\section{TIM EDITORIAL}

\section{EDITOR IN CHIEF}

1. Dr. Rais Hidayat

\section{REVIEWER}

1. Prof. Dr. Bibin Rubini, M.Pd.

2. Prof. Dr. Anna Permanasari, M.Si.

3. Prof. Dr. Thamrin Abdullah. MM., M.Pd.,

4. Prof. Dr. Marzuki ,M.Ed., M.A.,

5. Dr. Indarini Dwi Pursitasari,

6. Dr. Eri Sarimanah,

7. Dr. Bambang Sumintono,

8. Dr. Rhini Fatmasari,

9. Dr. Chaerul Rochman,

10. Dr. Risda Amini,

11. Dr. Idam Ragil Widianto Atmojo,

12. Dr. Erni Murniarti,

13. Dr. Irvan Permana, M.Pd.,

14. Dr. Eka Suhardi,

15. Dr. Henny Suharyati,

16. Dr. Griet Helena Laihad,

17. Dr. Rita Retnowati,

18. Dr. Endang Poerwanti, M.Pd.,

19. Dr. Abdul Muktadir,

20. Dr. Fitri Indriani,

21. Dr. Yuyun Elizabeth Patras
Universitas Pakuan, Bogor, Indonesia

Universitas Pakuan, Indonesia
Universitas Pendidikan Indonesia, Indonesia
Universitas Pakuan, Indonesia
Universitas Tanjungpura, Indonesia
Universitas Pakuan, Indonesia
Universitas Pakuan, Indonesia
University of Malaya, Malaysia
Universitas Terbuka, Indonesia
Universitas Islam Negeri Sunan Gunung Djati
Universitas Negeri Padang, Indonesia
Universitas Sebelas Maret, Indonesia
Universitas Kristen Indonesia, Indonesia
Universitas Pakuan, Indonesia
Universitas Pakuan, Indonesia
Universitas Pakuan, Indonesia
Universitas Pakuan, Indonesia
Universitas Pakuan, Indonesia
Universitas Muhammadiyah Malang, Indonesia
Universitas Bengkulu, Indonesia
Universitas Ahmad Dahlan, Indonesia
Universitas Pakuan, Indonesia

\section{EDITOR}

1. Didit Ardianto,

2. Sulfikar Sallu,

3. Desti Herawati,

4. Oding Sunardi,

5. Herfina,

6. Yudhie Suchyadi,

7. Yeyen Suryani,

8. Non Dwishiera Cahya Anasta,

9. Moh. Ali,

10. Iskandar,

11. Donna Sampaleng,

12. Dian Wulandari,

13. Huriah Rachmah,

\section{LAYOUT EDITOR \& IT SUPPORT}

1. Aries Maesya

2. Agung Prajuhana Putra

3. Windu Gata,

4. Agung Prajuhana Putra,

5. Muhamad Ginanjar Ganeswara,

6. Rizki Agung Dwihantoro,

7. Ade Irwan,
Universitas Pakuan, Indonesia

Universitas Sembilanbelas November Kolaka, Indonesia Universitas Pakuan, Indonesia Universitas Pakuan, Indonesia Universitas Pakuan, Indonesia Universitas Pakuan, Indonesia Universitas Kuningan, Indonesia Universits Pendidikan Indonesia, Indonesia Institut Agama Islam Negeri (IAIN) Palu, Indonesia Universitas Tadulako, Indonesia Sekolah Tinggi Teologi IKAT Jakarta, Indonesia Universitas Pakuan, Indonesia Universitas Islam Bandung, Indonesia

Universitas Pakuan, Indonesia Universitas Pakuan, Indonesia STMIK Nusa Mandiri, Indonesia Universitas Pakuan, Indonesia Universitas Pakuan, Indonesia Universitas Pakuan, Indonesia Universitas Pakuan, Indonesia 


\section{DITERBITKAN OLEH :}

SEKOLAH PASCASARJANA

JURNAL MANAJEMEN PENDIDIKAN

e-ISSN : 2614-3313

p-ISSN : 2302-0296

Universitas Pakuan, Bogor - Indonesia

\section{ALAMAT :}

Gedung Sekolah Pascasarjana, Universitas Pakuan,

Jalan Pakuan No 1, Ciheuleut, Kelurahan Tegalega, Kecamatan Bogor Tengah, Kota Bogor Indonesia - 16143

No. Telp. : +622518320123

No. Fax. : + +62251 8320123

e-mail : jmp@unpak.ac.id

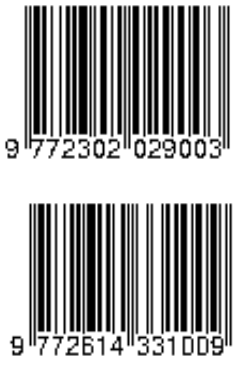




\section{Dari Editor}

\section{Selamat Datang di Jurnal Manajemen Pendidikan.}

Jurnal Manajemen Pendidikan adalah jurnal yang menerbitkan Artikel ilmiah di bidang manajemen pendidikan dan administrasi pendidikan. Jurnal ini diterbitkan oleh Sekolah Pascasarjana, Universitas Pakuan, Bogor. Jurnal ini memberikan kesempatan bagi para penulis ilmiah/peneliti dalam bidang manajemen pendidikan dan administrasi pendidikan untuk menerbitkan artikelnya. Kebijakan dari tim editor adalah hanya artikel yang terkait dengan bidang manajemen pendidikan dan administrasi pendidikan yang akan dipublikasikan secara online. Publikasi secara daring akan menambah kekayaan informasi dan pengetahuan ilmiah yang diperoleh terutama dari penelitian. Jurnal ini diterbitkan dua kali dalam satu tahun, didokumentasikan dengan baik dalam bentuk jurnal, yang mencakup berbagai artikel manajemen pendidikan dan administrasi pendidikan oleh penulis dari berbagai latar belakang. Selain itu, kami juga memiliki mitrabestari dari Universitas Pakuan beserta dari beberapa universitas lain yang kompeten meninjau setiap artikel sebelum dipublikasikan. Setiap artikel yang diterbitkan dalam Jurnal ini akan bermanfaat bagi semua pengunjung dan pembaca.

\section{Pengindeksan}

Crossref

On E Search

\section{Cogaruda PKP|index Goggle}

publons

\section{$R \partial A D=D$ Dimensions}

\section{Perangkat Artikel}

\section{turniting) EndNote G grammarly (요 MENDELEY}

\section{Menggunakan gaya kutipan APA}

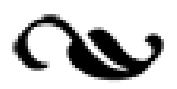

APA

STYLE 


\section{DAFTAR ISI}

EVALUASI PELATIHAN DASAR CALON PEGAWAI NEGERI SIPIL DALAM MENDUKUNG TERWUJUDNYA SUMBERDAYA MANUSIA PROFESIONAL BERKARAKTER Rahmi Astuti Rohaini, Nandang Hidayat, Entis Sutisna

PENGEMBANGAN MODEL PEMBELAJARAN PIPI MAMA DALAM MENINGKATKAN KETERAMPILAN WRITING DI SEKOLAH MENENGAH PERTAMA (SMP)

PENINGKATAN PRODUKTIVITAS KERJA GURU MELALUI PENGEMBANGAN SUPERVISI KEPALA SEKOLAH DAN KREATIVITAS KERJA Wahyuni Wahyuni, M Entang, Herfina Herfina

PENINGKATAN EFEKTIVITAS MANAJEMEN PEMBELAJARAN GURU MELALUI PENGEMBANGAN BUDAYA KERJA DAN KOMITMEN ORGANISASI Kamaludin Kamaludin, Sri Setyaningsih, Adie E Yusuf

PENINGKATAN KEINOVATIFAN MELALUI PENGEMBANGAN KEPEMIMPINAN TRANSFORMASIONAL DAN EFIKASI DIRI

Sendy Sunardi, Widodo Sunaryo, Griet Helena Laihad

HUBUNGAN KEPEMIMPINAN SITUASIONAL KEPALA SEKOLAH DAN KEPERCAYAAN PADA ORGANISASI DENGAN KEPUASAN KERJA

Sopyan Sopyan, Bibin Rubini, Griet Helena Laihad

PENGEMBANGAN MODEL IN-HOUSE TRAINING BERBASIS INTERNET MENINGKATKAN KEMAMPUAN MENGAJAR GURU TAMAN KANAK-KANAK 